\title{
RADIOCARBON RESULTS FOR THE BRITISH BEAKERS
}

\author{
JANET AMBERS ${ }^{1}$, SHERIDAN BOWMAN ${ }^{1}$, ALEX GIBSON ${ }^{2}$ and IAN KINNES ${ }^{3}$
}

\begin{abstract}
The beginning of the Bronze Age in the British Isles has traditionally been marked by the appearance, in the archaeological record, of Beaker assemblages, mainly characterized by the Beaker pottery form itself. Ceramic typologies based on this style, which is undoubtedly continental in origin, have been used both for relative dating and as evidence of the social and economic developments of the period. Systematic radiocarbon dating has been attempted for the continental European Beaker material (Lanting, Mook \& van der Waals 1973), but no such program has been carried out on British material. An examination of the existing radiocarbon results for the British Beakers showed many to be flawed in some way, particularly in the use of materials, such as mature wood, where there is no a priori reason for assuming a direct relationship between sample death and context. An attempt has been made at the British Museum to test the validity of archaeologically derived chronologies for the Beaker pottery of the British Isles. This involved analysis of a group of carefully selected human bone samples from Beaker burials, where there is a known direct association between ceramic usage and the cessation of carbon exchange. Twenty such samples have been identified and measured. The results presented here, combined with other previously produced determinations, show no obvious relationship between pottery style and calendar date of deposition.
\end{abstract}

\section{INTRODUCTION}

In the 40 years since Libby's first ${ }^{14} \mathrm{C}$ measurements, the use of radiocarbon has radically altered archaeological chronologies and our perceptions of the past. It provided the first absolute means of dating those sites and cultures which are truly prehistoric, and now, post the production of reliable calibration curves, it gives a means of relating archaeological phenomena to the calendrical scale.

Despite this, ${ }^{14} \mathrm{C}$ dating has not solved all our chronological problems. This is due partly to unavoidable difficulties; there will always be gaps in material availability, and measurement precision will always be limited by physical laws and technical possibilities. In addition, the variation in ${ }^{14} \mathrm{C}$ production, reflected in the calibration curve, places immutable limitations on the applications of radiocarbon dating to archaeology. There are, however, other avoidable reasons for difficulties within radiocarbon-derived archaeological chronologies. Most of these can be put into two categories: first, a lack of scientific rigor in the selection of samples for dating; and second, a widespread over-optimism among laboratories about the precision and accuracy of their analyses. This study reflects an attempt to overcome both these pitfalls and to solve a specific archaeological problem by careful and controlled use of radiocarbon as a dating tool.

\section{BRITISH BEAKERS: THE ARCHAEOLOGICAL FRAMEWORK}

This work relates to the period at the beginning of the first half of the fourth millennium BP, marked by the introduction to Britain of new pottery styles, notably the Beaker form itself, and of metal working. Most of the evidence for this period has come from graves, normally single inhumations, each accompanied by a Beaker; finds of occupation material do exist but are seldom linked with any structural evidence. The Beaker pottery form is distinctive, defined by an S-shaped profile with frequent, and often very attractive, use of various forms of geometric decoration. It is not wheel thrown, but is of fine materials with a generally high standard of manufacture, and each vessel required a large input of effort; it has been estimated that some of the Dutch Beakers took 4-6 h, excluding clay preparation and drying and firing the finished product (Clarke 1970).

\footnotetext{
${ }^{1}$ Department of Scientific Research, British Museum, London WC1B 3DG, UK

${ }^{2}$ Clwyd-Powys Archaeological Trust, Welshpool, Powys S42 7DL, UK

${ }^{3}$ Department of Prehistoric and Romano-British Antiquities, British Museum, London WC1B 3DG, UK
} 
The style is widespread throughout continental Europe, where the origins of the British material seem to lie, but the mechanism for the introduction and the way in which it might be possible to subdivide the corpus of material into typologies, and by inference, into chronological groups has been a cause of debate. The most influential such study is the massive work of Clarke (1970), in which he collated and illustrated a large body of data, including all the Beaker material known at that time. Based on an analysis of the non-functional aspects of the pottery form,including size, exact shape and decoration, he suggested the immigration into the British Isles of seven different Beaker making groups in two main phases. Each group would be distinguishable by a particular pottery style, followed by the development of two distinctive native pottery traditions, each again divisible into typological and chronological groups. Since Clarke's seminal publication, several attempts have been made to rework the same data, notably by Lanting and van der Waals (1972) who, as Dutch archaeologists, had the advantage of coming to the material when already familiar with the continental forms. They presented a scheme involving only one continental influx into the British Isles, followed by the development of regional styles, in seven developmental stages.

As is apparent from this, Beaker pottery styles have long been associated with chronological periods, and they have been used widely within British archaeology to date and sequence those sites on which they appear. What has been lacking until now is any concerted attempt to validate this assumption, although Lanting, Mook and van der Waals (1973) attempted a similar process for the European lowlands. In this paper, we attempt to fill this gap.

\section{SAMPLE SELECTION}

It is a truism that all a radiocarbon result can ever date is the time at which the carbon of the material analyzed ceased to exchange with its environment. Despite widespread lip service to this fact, with a few admirable exceptions, sample selection for archaeological dating has seldom been rigorous, and the excellent guidelines set out by Waterbolk as long ago as 1971 have seldom been fully applied. To an extent, this has been due to a tendency by laboratories, even those specifically concerned with archaeology, to regard themselves as principally measurement services, and to assign the responsibilities for sample integrity and selection to the archaeologist. In this study, the opportunity arose for radiocarbon scientists and archaeologists to work together to produce a reliable group of sample materials which could be used to answer specific problems.

Two questions may be asked of any possible radiocarbon sample at the earliest stage: 1) does it come from a known, firm archaeological context? and 2) can its ${ }^{14} \mathrm{C}$ content be directly related to an archaeological event? In attempting to date the British Beaker series, it is possible to provide samples that fulfill both of these criteria. An intact burial of articulated bone is about as firm and controlled a context as it is possible to find in archaeology, with any post-depositional disturbance likely to be reflected by some disturbance of the skeleton itself.

The analysis of materials that cannot directly reflect the age of the context in which they are found has been the cause of much confusion in the use of radiocarbon for archaeological dating. In particular, frequent use of wood samples of unknown and unquantifiable initial age has undermined many efforts to give firm dating frameworks. Here again, dating an inhumation has many advantages. Providing it is possible to isolate a chemically unaltered fraction from the bone, a radiocarbon result on human bone from a burial must relate directly to the time of death of that individual. If the inhumation is articulated, then appreciable delay in archaeological terms between death and burial is unlikely. Radiocarbon analysis of bone from an articulated human burial can therefore be reliably assumed to date the time of that burial and the deposition of any accompanying grave goods. To relate this figure to the period of normal currency of such pottery 
is, of course, speculative. There are many possible reasons why it may not reflect non-funerary trends including the use of heirlooms or the deliberate production of archaic styles solely for burial purposes, or simply the opportunistic disposal of unwanted objects, but the result certainly provides a calendar date for ultimate usage.

The requirement, in this study, for a large number of long bones from articulated burials securely associated with known Beaker types meant that most of the samples would have to come from previously excavated collections, which were both adequately recorded and provenanced, and available for destructive analysis. In practice, this severely limited the number of samples available. Some material that fulfilled these criteria was then rejected on technical grounds by the laboratory because of poor protein survival, or because of previous conservation treatment. Whereas bone is, in many ways, an ideal sample material, it has some well-documented technical drawbacks, resulting from post-depositional chemical changes. With the development of small counter techniques and the processing of increasing numbers of collagen dates, it has become apparent that not even all results on proteinaceous extracts are reliable (see e.g., Long et al. 1989; Gillespie 1989). There is, however, general agreement that contamination problems large enough to be important within the precision of conventional ${ }^{14} \mathrm{C}$ analysis only occur when the collagen survival is poor. Bearing all this in mind, we decided to include, in this study, only material from single human long bones, from articulated well-provenanced burials, clearly associated with Beaker pottery, where the extracted protein was well-preserved, giving a clear pseudomorph of the original material. This stringency in sample selection meant that, of the projected 40-50 samples originally envisaged, only 20 were ultimately measured.

\section{LABORATORY RELIABILITY, ACCURACY AND PRECISION}

In light of successive Glasgow University intercomparison studies (International Study Group 1982; Scott et al. 1990), it has become uncomfortably apparent that laboratory reliability and precision have been widely overestimated in the past. This lesson has been particularly learned at the BM Laboratory, where analysis of the results of the first Glasgow study was, at least partially, responsible for the identification of an error, and the withdrawal, recalculation and, where possible, re-issue of some 470 results produced between 1980 and 1984 (Tite et al. 1988). The reasons for this error, and the way in which the revised figures were generated, is published fully (Bowman, Ambers \& Leese 1990) and will not be repeated here, but its salutary effect can easily be imagined. Efforts at the British Museum have, therefore, been concentrated on improving the counting system and installing checks to ensure that such a situation does not recur. These measures have been reported in other papers (Bowman \& Ambers, in press), and are briefly summarized in Table 1, which lists the results for the first counting run of a series of samples of dendrochronologically dated wood, kindly supplied by Drs. Baillie and Pilcher, of Queen's University, Belfast. Each result is for independent, synthesized and counted raw material. The Belfast high-precision measurements for wood of the same date (Pearson et al. 1986) are also given. At least one such known-age sample is included in each counting run, with regular replacement to ensure no distortion by sample evaporation. This procedure effectively fulfills the quality assurance proposals included in Long (1990), but its institution precedes that publication. The close agreement between BM and Belfast analyses is clear, and serves to support a claim by the British Museum Laboratory that the results produced are accurate and the precision quoted is justifiable.

\section{MEASUREMENT PROCEDURES AND RESULTS}

All of the samples in this series were selected to be of reasonably well-preserved bone, and were treated with dilute acid to extract "collagen" (here defined as the acid-insoluble fraction of bone 
TABLE 1. Comparison of British Museum and Belfast ${ }^{14} \mathrm{C}$ analyses for dendrochronologically dated oak samples*

\begin{tabular}{lccc}
\hline $\begin{array}{c}\text { British Museum results BP** } \\
\text { (unrounded) }\end{array}$ & $\begin{array}{c}\text { Weighted mean } \\
\pm \text { std. error BP }\end{array}$ & $\begin{array}{c}\text { Belfast result BP } \\
\text { (Pearson } \text { et al. 1986) }\end{array}$ \\
\hline BM-2494 & $2879 \pm 39$ & & $2886 \pm 12$ \\
BM-2493 & $2835 \pm 37$ & $2876 \pm 21$ & \\
BM-2562 & $2920 \pm 53$ & & \\
BM-2747 & $2869 \pm 47$ & & \\
BM-2746 & $1059 \pm 52$ & & $1020 \pm 17$ \\
BM-2563 & $1017 \pm 44$ & $1020 \pm 13$ & \\
BM-2564 & $1060 \pm 45$ & & \\
BM-2432 & $1029 \pm 47$ & & \\
BM-2432L & $999 \pm 37$ & & \\
BM-2745 & $981 \pm 44$ & & \\
BM-2560 & $4364 \pm 47$ & & \\
BM-2561 & $4362 \pm 45$ & & \\
BM-2580 & $4337 \pm 43$ & $4357 \pm 23$ & \\
BM-2616 & $4368 \pm 48$ & & \\
\hline
\end{tabular}

*These figures are for the first $2000 \mathrm{~min}$ count time of each independently generated sample.

**Samples were counted quasi-simultaneously, in 1 of 3 counters, in trains including at least 2 modern and 2 background samples, with standards being replaced regularly but at staggered intervals. Samples are made up of $5.5 \mathrm{ml}_{6} \mathrm{H}_{6}$ with $15 \mathrm{gl}^{-1}$ butyl PBD.

${ }^{\dagger}$ All samples are separately synthesized from raw wood except BM-2432 and BM-2432L, separate aliquots of the same benzene, counted in different counters.

rather than the true biochemical definition). Only this collagen fraction was dated. After pretreatment, the cleaned samples were converted to benzene and analyzed by conventional liquid scintillation counting, using the cocktail and configuration described in Ambers, Matthews and Bowman (1989).

The results of the British Museum program are quoted in Table 2, together with calibrations based on $68 \%$ and $95 \%$ confidence, using the curves of Pearson \& Stuiver (1986) and Pearson et al. (1986) and Method B of CALIBM, an adaptation of revision 2.0 of the University of Washington Quaternary Laboratory Radiocarbon Calibration Program (Stuiver \& Reimer 1987) for the in-house computer of the British Museum Department of Scientific Research. This program uses the probability method of calibration. Errors quoted are the counting error for the sample combined with an estimate of the errors contributed by the modern and background samples. This estimate includes both counting and non-counting errors, the latter being computed from differences in the overall count rates observed among the individual backgrounds and moderns. All results are quoted in the form recommended by Stuiver \& Polach (1977) in uncalibrated years BP (before 1950), and corrected for measured isotopic fractionation.

Calibrated dates are quoted in the form recommended in Mook (1986). The end points of the calibrated date ranges have been rounded outwards to five years. An effect of this rounding process is to slightly overestimate the possible calendar ranges given. Calibrations are depicted graphically in two ways; as simple line plots showing the $68 \%$ and $95 \%$ confidence limits and, where space allows, as probability distributions. 


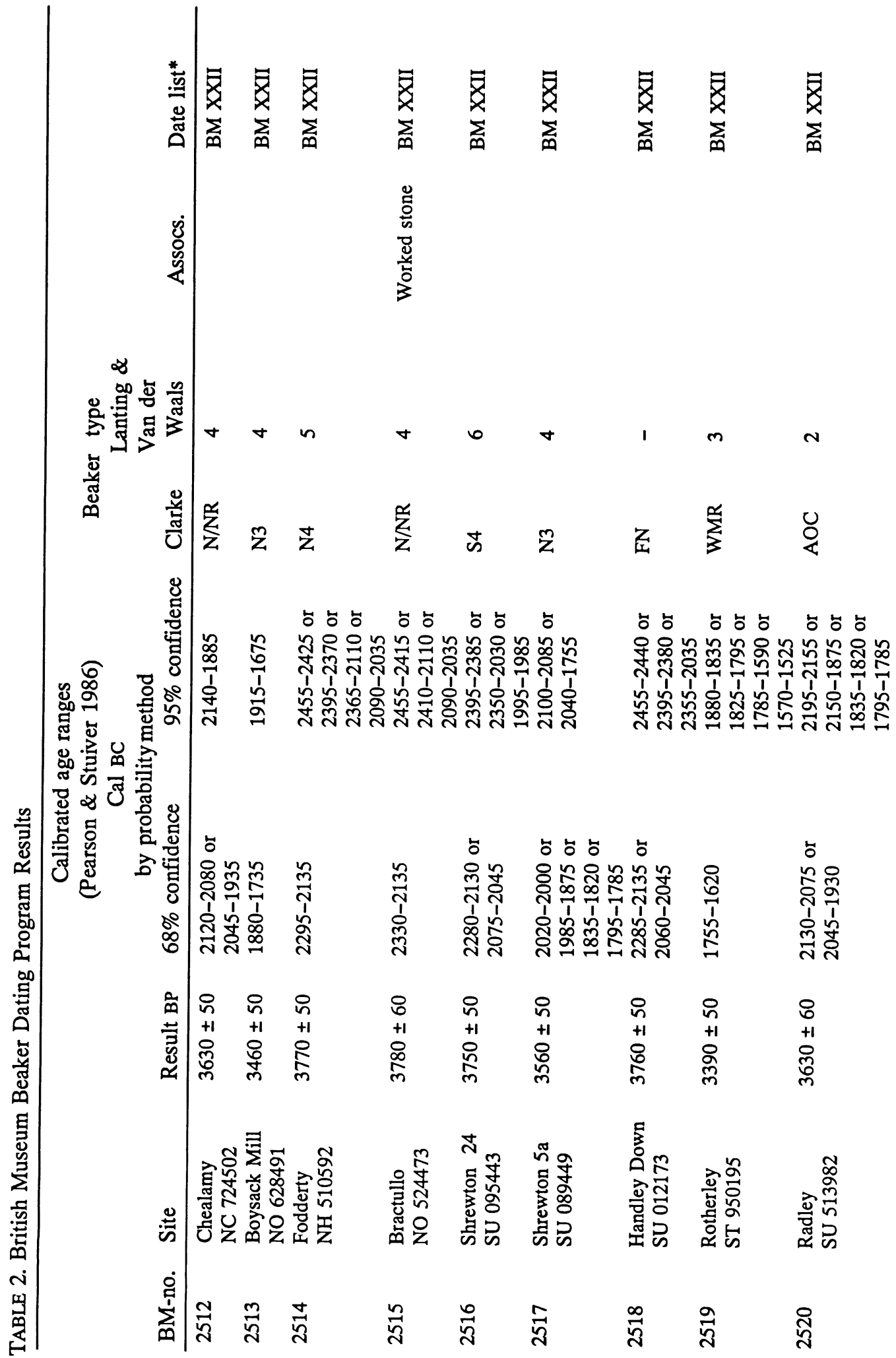




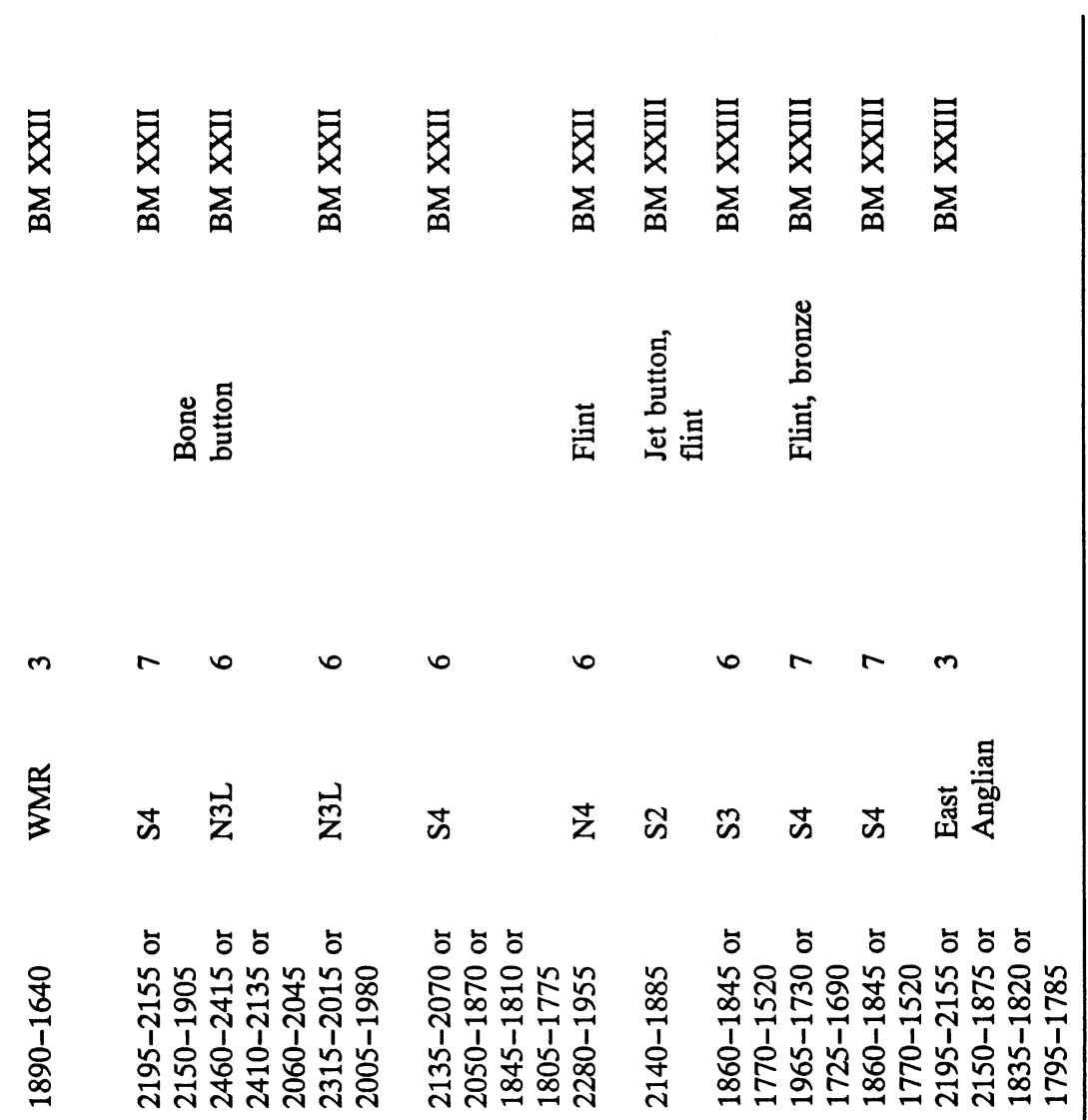

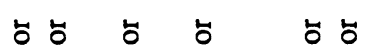

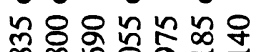

元

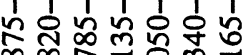

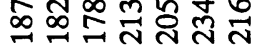

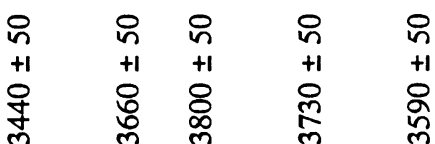

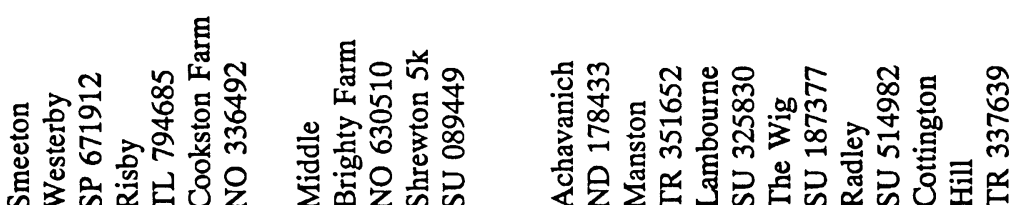

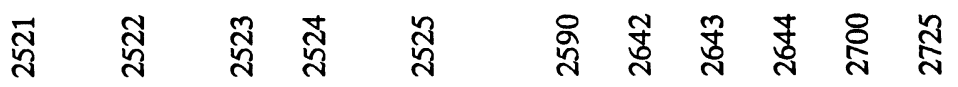

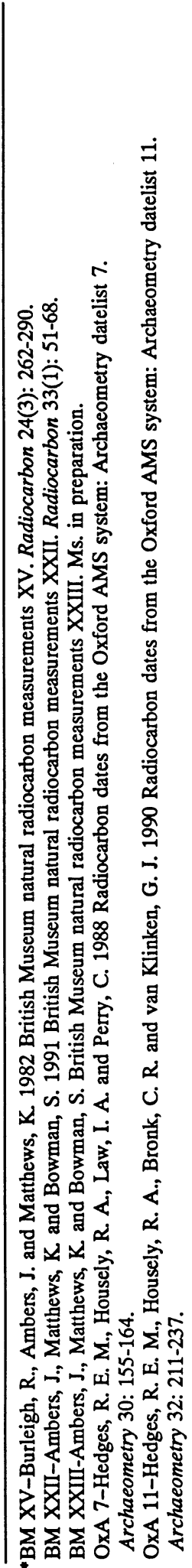




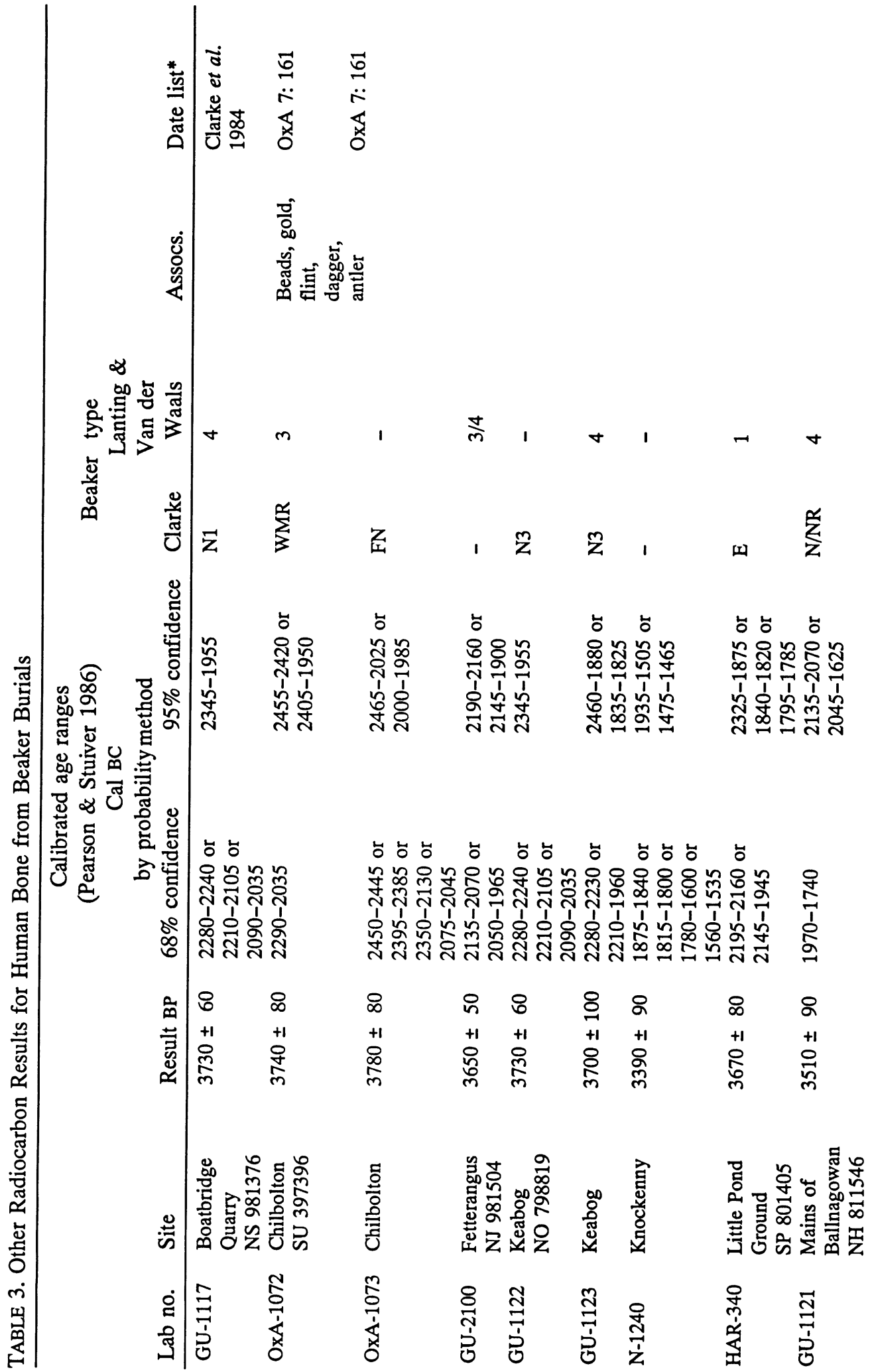




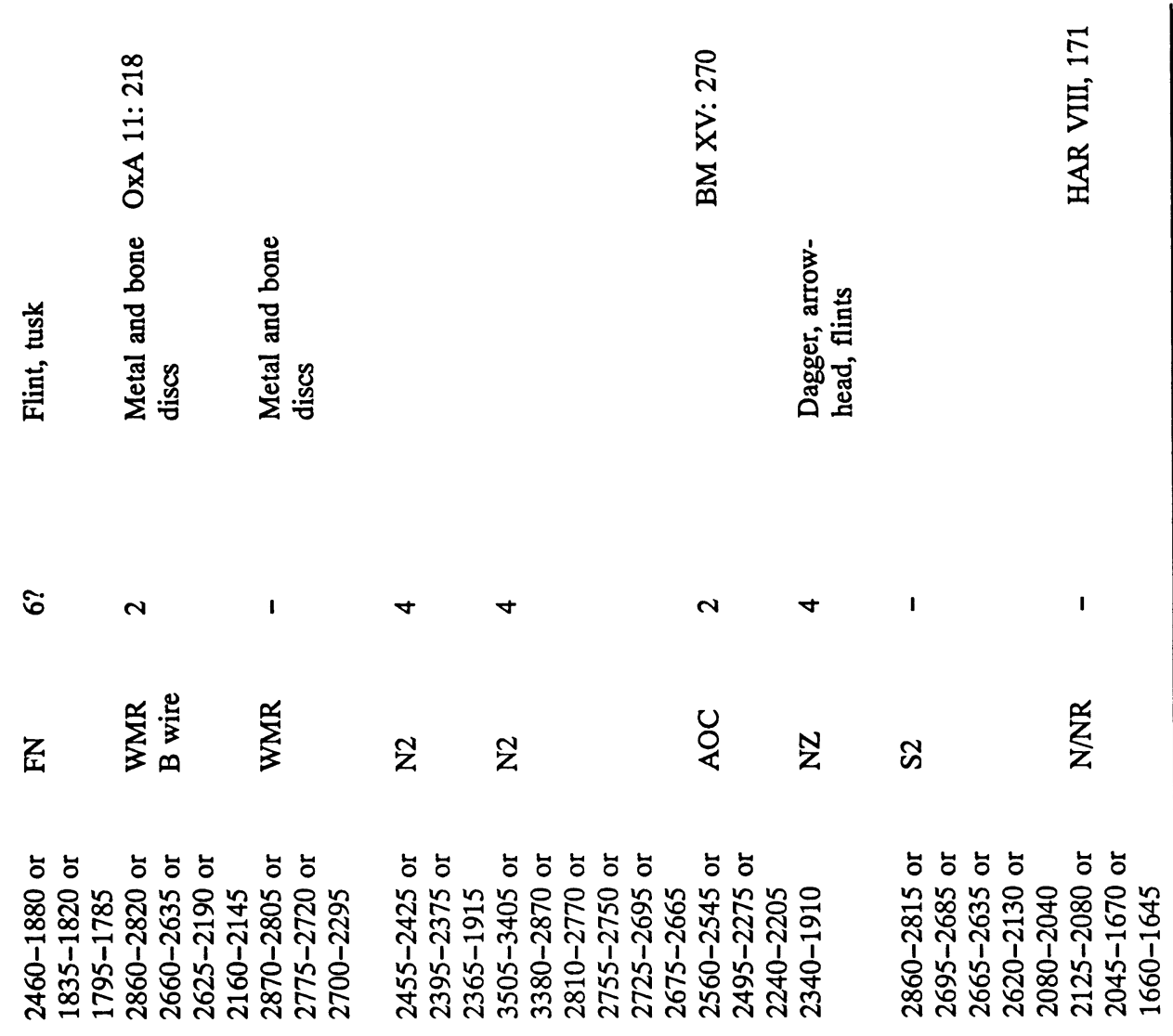

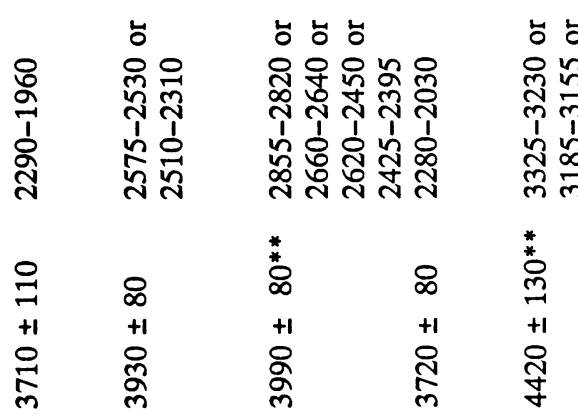

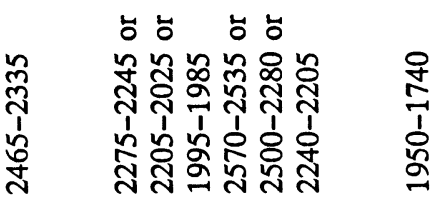

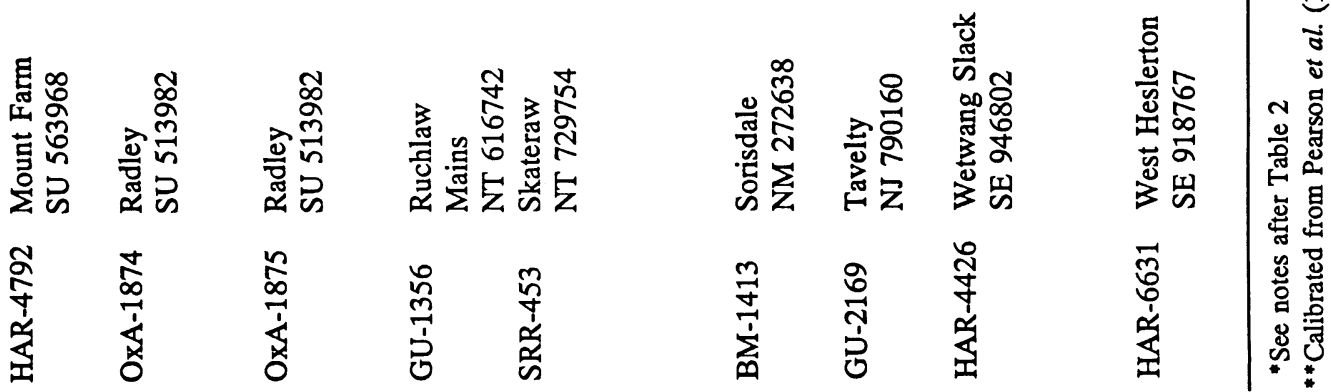



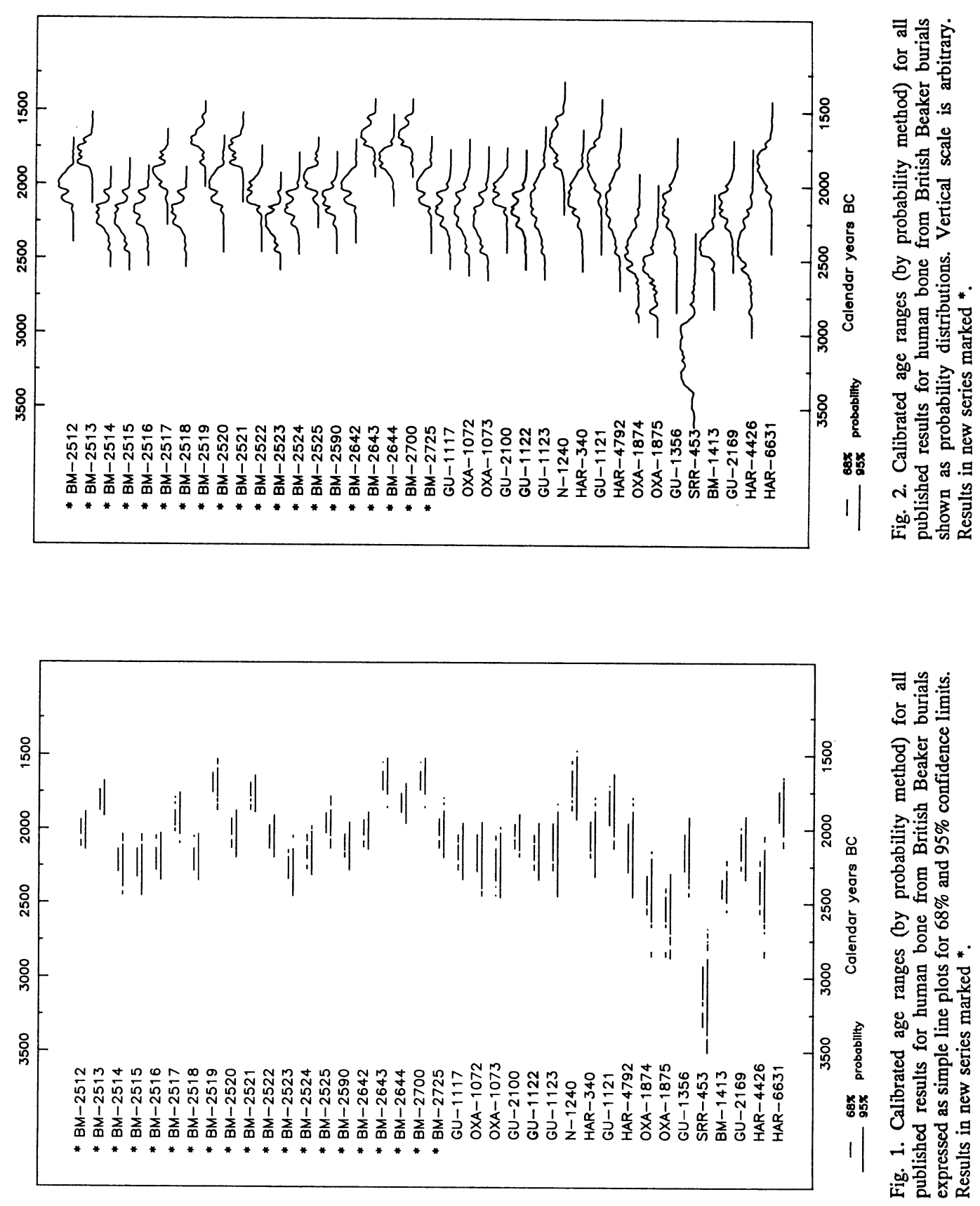


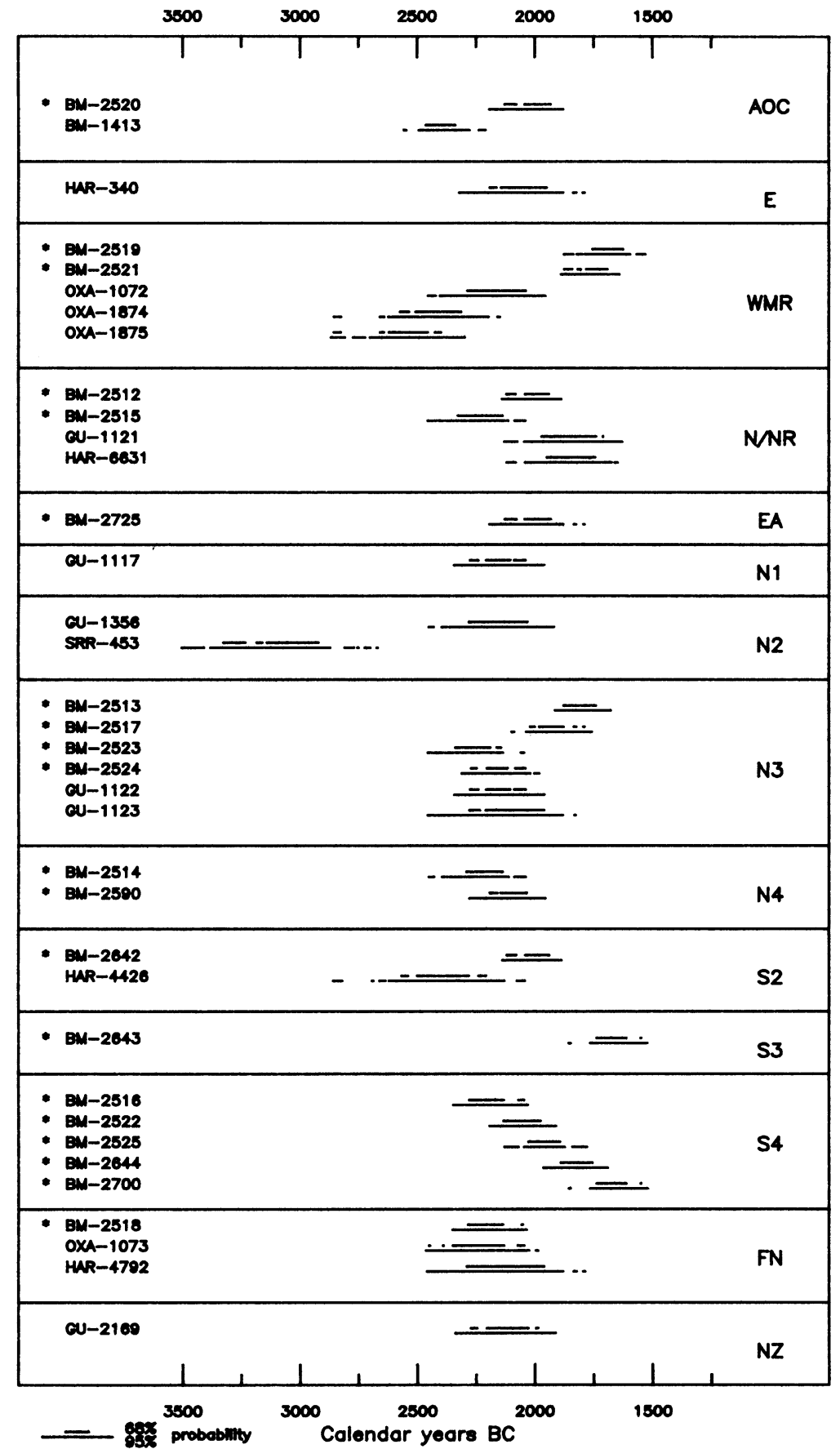

Fig. 3. Calibrated age ranges (by probability method) for all published results for human bone from British Beaker burials expressed as simple line plots for $68 \%$ and $95 \%$ confidence limits, subdivided by Clarke's Beaker types. Results in new series marked * 


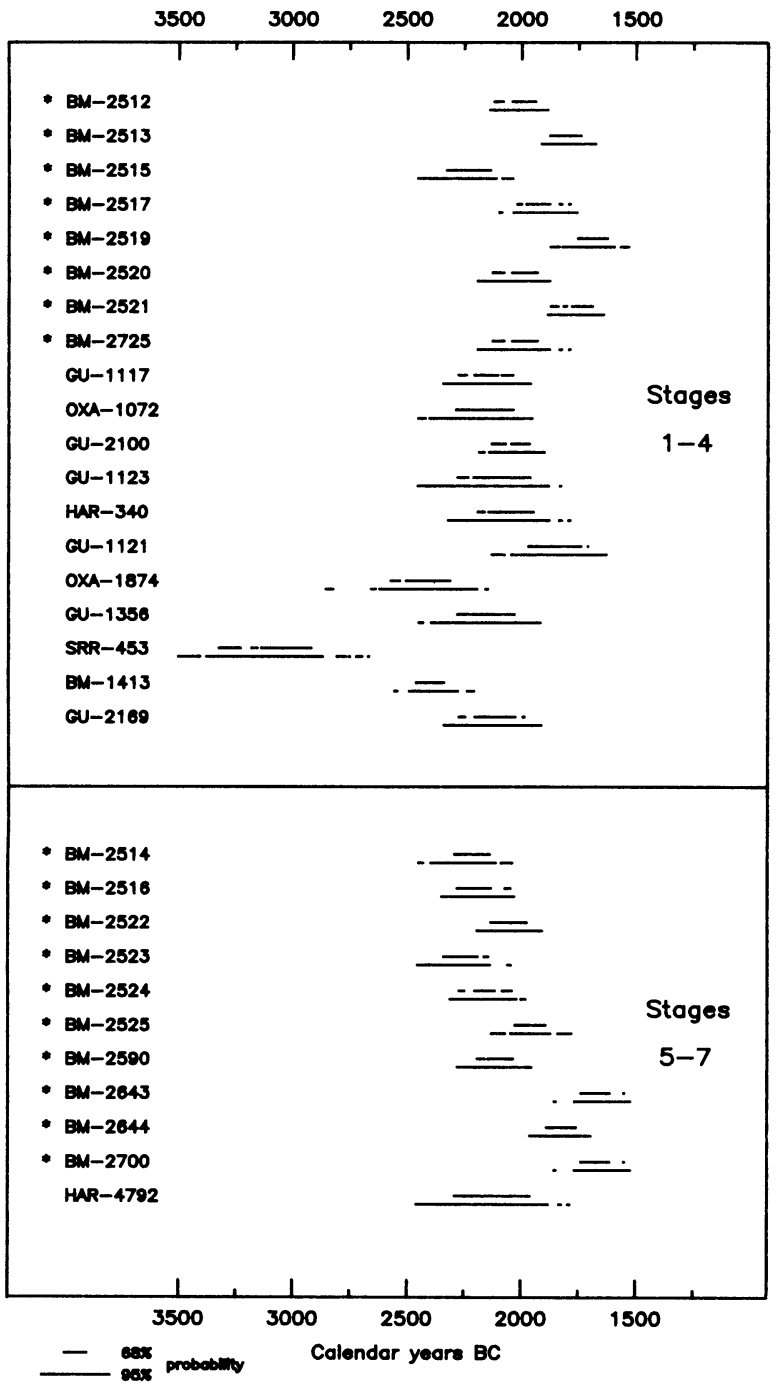

Fig. 4. Calibrated age ranges for all published results for human bone from British Beaker burials expressed as simple line plots for $68 \%$ and $95 \%$ confidence limits, subdivided by Lanting and van der Waals developmental steps. Results in new series marked *.

Results for human bone from British Beaker burials produced by other laboratories or by the British Museum, but not as part of this study, are also listed in Table 3, together with calibrations. Given the results of the intercomparison studies, it could be argued that many of these figures were not necessarily generated under conditions that would pass the Long et al. (1989) criteria, and so cannot be justifiably combined with those of the new BM series. We include them here for completeness, but for clarity in the diagrams, we have distinguished all the new BM analyses with *.

\section{Discussion}

The full archaeological implications of these data will be discussed elsewhere (Kinnes et al. 1991), but some points can be made here. All the published ${ }^{14} \mathrm{C}$ analyses listed in Tables 2 and 3 are shown plotted as simple line and as probability distributions in Figures 1 and 2 . The same data are shown in Figures 3 and 4 but divided into Clarke Beaker types, and Lanting and van der Waals stages. No connection between typology and absolute chronology is obvious in either of these two 
arrangements, although the width of the calibrated ranges may conceal some trends. On this evidence, the use of such classifications as chronological indicators would be misleading.

This work emphasizes the requirement for strict and careful control of sample selection and measurement procedures if ${ }^{14} \mathrm{C}$ results are to be used in archaeological reconstruction. A full literature search for ${ }^{14} \mathrm{C}$ analyses for the British Beakers yielded a total of 124 results with the great majority of these being on charcoal, frequently unidentified, or on other material with the possibilities of age offset. Use of such results without due regard to their limitations serves only to cloud the archaeological picture.

\section{ACKNOWLEDGMENTS}

Thanks are due to those colleagues who allowed sampling from their collections and to Tony Simpson for help in preparation of the figures.

\section{REFERENCES}

Ambers, J., Matthews, K. and Bowman, S. 1989 British Museum natural radiocarbon measurements XXI. Radiocarbon 31(1): 15-32.

Bowman, S. G. E. and Ambers, J. C., in press, Past and present: The identification of an error in, and the present status of, radiocarbon dating at the British Museum. In Waterbolk, H. T. and Mook, W. G., eds., Proceedings of the 2nd International Symposium on Archaeology and ${ }^{14} \mathrm{C}$. PACT.

Bowman, S. G. E., Ambers, J. C. and Leese, M. N. 1990 Re-evaluation of British Museum radiocarbon dates issued between 1980 and 1984. Radiocarbon 32(1): 59-80.

Clarke, D. L. 1970 The Beaker Pottery of Great Britain and Ireland. Cambridge, Cambridge University Press.

Gillespie, R. 1989 Fundamentals of bone degradation chemistry: Collagen is not "the way." In Long, A. and Kra, R. S., eds., Proceedings of the 13th International ${ }^{14} \mathrm{C}$ Conference. Radiocarbon 31(3): 239-246.

International Study Group 1982 An inter-laboratory comparison of radiocarbon measurements in tree rings. Nature 298: 619-623.

Kinnes, I., Gibson, A., Ambers, J., Leese, M., Bowman, S., and Boast, R. 1991 Radiocarbon dating and British Beakers: The British Museum programme. Scottish Archaeological Forum 8: 000-000.

Lanting, J. N., Mook, W. G. and Waals, J. D. van der $1973{ }^{14} \mathrm{C}$ chronology and the Beaker problem. Helinium 13: 38-68.

Lanting, J. N. and Waals, J. D. van der 1972 British Beakers as seen from the continent. Helinium 12: 20-46.

Long, A., compiler, 1990 A quality assurance protocol for radiocarbon dating laboratories. In Scott, E. M., Long, A. and Kra, R. S., eds., Proceedings of the International Workshop on Intercomparison of ${ }^{14} \mathrm{C}$ Laboratories. Radiocarbon 32(3): 393-397.

Long, A., Wilson, A. T., Ernst, R. D., Gore, B. H. and
Hare, P. E. 1989 AMS radiocarbon dating of bones at Arizona. In Long, A. and Kra, R. S., eds., Proceedings of the 13 th International ${ }^{14} \mathrm{C}$ Conference. Radiocarbon 31(3): 231-238.

Mook, W. G. 1986 Business meeting: Recommendations/resolutions adopted by the Twelfth International Radiocarbon Conference. In Stuiver, M. and Kra, R. S., eds., Proceedings of the 12 th International ${ }^{14} \mathrm{C}$ Conference. Radiocarbon 28(2A): 799.

Pearson, G. W., Pilcher, J. R., Baillie, M. G. L., Corbett, D. M. and Qua, F. 1986 High-precision ${ }^{14} \mathrm{C}$ measurements of Irish oaks to show the natural ${ }^{14} \mathrm{C}$ variations from AD 1840-5210 BC. In Stuiver, M. and Kra, R. S., eds., Proceedings of the 12th International ${ }^{14} \mathrm{C}$ Conference. Radiocarbon 28(2B): 911-934.

Pearson, G. W. and Stuiver, M. 1986 High-precision calibration of the radiocarbon time scale, 500-2500 BC. In Stuiver, M. and Kra, R. S., eds., Proceedings of the 12 th International ${ }^{14} \mathrm{C}$ Conference. Radiocarbon 28(2B): 839-862.

Scott, E. M., Aitchison, T. C., Harkness, D. D., Cook, G. T. and Baxter, M. S. 1990 An overview of all three stages of the International Radiocarbon Intercomparison. In Scott, E. M., Long, A. and Kra, R. S., eds., Proceedings of the International Workshop on Intercomparison of ${ }^{14} \mathrm{C}$ Laboratories. Radiocarbon 32(3): 309-320.

Stuiver, M. and Polach, H. J. 1977 Discussion: Reporting of ${ }^{14} \mathrm{C}$ data. Radiocarbon $19(3)$ : $355-363$.

Stuiver, M. and Reimer, P. J. 1987 User's Guide to the Programs CALIB and DISPLAY, Rev. 2.1. Quaternary Isotope Laboratory, University of Washington.

Tite, M. S., Bowman, S. G. E., Ambers, J. C. and Matthews, K. J. 1988 Preliminary statement on an error in British Museum radiocarbon dates (BM-1700 to BM-2315). Radiocarbon 30(1): 132.

Waterbolk, H. T. 1971 Working with radiocarbon dates. Proceedings of the Prehistoric Society 37: 15-33. 